\title{
Therapeutic Drug Monitoring of Tacrolimus in Saudi Kidney Transplant Patients
}

\author{
Marzog S Al-Nasser ${ }^{1^{*}}$, Ahmed S Ali ${ }^{2}$, Mai A Abdul Sattar ${ }^{2}$, Ezz H Abdulfattah ${ }^{3}$, Lateef M Khan ${ }^{2}$ and Khalid Abdullah Al-Alsheikh ${ }^{1}$ \\ ${ }^{1}$ Armed Forces Hospital, Southern Region, Khamis Mushate, Saudi Arabia \\ ${ }^{2}$ Clinical Pharmacology Department, Faculty of Medicine, King Abdulaziz University, Jeddah, Saudi Arabia \\ ${ }^{3}$ Statistics Department, Faculty of Sciences, King Abdulaziz University, Jeddah, Saudi Arabia
}

*Corresponding author: Marzog Saeed AL Nasser, Armed Forces Hospital, Southern Region, Khamis Mushate, P.O. Box 101 , Kingdom of Saudi Arabia, Tel: +966 557775975; E-mail: ph_marzog@hotmail.com

Received date: October 25, 2016; Accepted date: October 29, 2016; Published date: October 31, 2016

Copyright: (c) 2016 AL-Nasser MS, et al. This is an open-access article distributed under the terms of the Creative Commons Attribution License; which permits unrestricted use; distribution; and reproduction in any medium; provided the original author and source are credited.

\begin{abstract}
Background: Tacrolimus is immunosuppressive agent used for the prevention of rejection in kidney transplant patients, has narrow therapeutic range, and variable pharmacokinetics.
\end{abstract}

Objectives: To identify the optimum Tacrolimus blood trough level for Saudi kidney transplant patients (SKTP).

Method: The research population consisted of 100 SKTP at the Armed Forces Hospital in the Southern Region (AFHSR) treated with Tacrolimus and followed-up for a period of 24 months (2012 till 2014).

Results: A significant relationship between Tacrolimus trough level and incidence of kidney rejection was remarkably found only after 180 days post-transplantation. During this period, Tacrolimus mean trough level (ng/ml) was $7.4 \pm 0.2$ in SKTP with no rejection, $5.3 \pm 0.7$ for those with acute rejection, and $3.8 \pm 0.4$ for those with chronic rejection. Furthermore, the coefficient of variation (CV\%) which reflects fluctuation in Tacrolimus trough level, was obviously high in SKTP with acute rejection in all post-kidney-transplant periods.

Conclusion: After 6 month post- kidney transplantation in SKTP, Tacrolimus trough level $(<5 \mathrm{ng} / \mathrm{ml} \mathrm{can}$ lead to graft loss, great fluctuation in its level is a major risk factor in incidence of rejection. Further research at genetic level is needed to guide optimal dosing in the early period post transplantation.

Keywords: Tacrolimus; Immunosuppressive; Kidney transplant; Saudi

\section{Introduction}

Organ transplantation requires lifelong pharmacotherapy with combination of immunosuppressant drugs which include a steroid, and immune modulator (e.g. mycophenolate mofetil, and a calcineurin inhibitor (CNI) like cyclosporine A and Tacrolimus [1].

Tacrolimus became an essential component of immunosuppressant regimens in most transplant centers. Its mechanism involve selective suppression of T-lymphocyte and its pharmacokinetic is quite variable among individuals and influenced by so many variables such as race, time after transplantation and other chronic illness. It is extensively metabolized in the liver by cytochrome P450 3A system (CYP3A), which is subject to considerable inter-individual variation and drug interaction [2]. It produces many adverse reactions which include infections, malignancies, nephrotoxicity, hypertension and diabetes mellitus [3]. Furthermore, Tacrolimus is liable for several drug interactions, primarily with agents affecting the cytochrome P-450 system which include food and herbal medicines. These interactions may lead to serious toxicity or rejection of the transplanted organ [3]. Tacrolimus has narrow therapeutic window; under dosing is associated with an increased risk for rejection, whereas overdosing is associated with higher incidence of dose related toxicity [4].
Therefore therapeutic drug monitoring (TDM) service which include monitoring of Tacrolimus trough level (the level just before the next dose), in conjunction with other laboratory and clinical parameters and screening for potential drug interaction is an essential tools to optimize treatment outcomes in transplant patients $[5,6]$.

The aim of present study is to explore the role of trough level monitoring to optimize use of Tacrolimus in SKTP.

\section{Method}

A retrospectively was done during 2012 till 2014, all adult Saudi kidney transplant patients who were followed-up in Kidney Transplant Centre in Armed Forces Hospital in the Southern Region are legible for inclusion in the present study.

\section{Inclusion criteria}

All adult patients of either sex, in the age group of 18-60 years, recipient of only first renal transplant and those on immunosuppressant therapy comprising of Tacrolimus, MMF and Prednisolone only were included in the study. 
Page 2 of 5

\section{Exclusion criteria}

Patients with more than one kidney transplant procedure or who use other immune suppression regimen or Cyclosporine based immunosuppressive therapy. Also patients who show poor drug compliance record or not attend regularly for follow up as scheduled were excluded.

\section{Implemented Tacrolimus protocol in AFHSR}

At the AFHSR in Khames Mushait (Saudi Arabia), the initial Tacrolimus orally dose taken is $0.1 \mathrm{mg} / \mathrm{kg} /$ day (two divided doses) and subsequently adjusted as guided by assessment of the patients which includes scheduled Tacrolimus trough level determination (in view of international; guidelines). the following target of Tacrolimus trough level were implemented in SKTP which depend on post transplantation time: $1-14$ days $(10-12 \mathrm{ng} / \mathrm{ml}), 15-28$ days $(8-10 \mathrm{ng} /$ $\mathrm{ml}), 29$ days to 180 days $(6-8 \mathrm{ng} / \mathrm{ml})$ and from 180 days onward (5-7 $\mathrm{ng} / \mathrm{ml})$.These reference range according to transplant protocol which approved by kidney transplant centre in AFHSR.

\section{Outcome measurement}

Parameters used for measurement of outcomes in this study included: acute and chronic rejection kidney rejection as indicated by clinical manifestations (i.e. graft enlargement, fever, malaise, hypertension, oliguria and decreased renal clearance), biopsy test and histo-pathological findings. Furthermore, post-transplant NODM, hypertension, nephrotoxicity and neurotoxicity were recorded.

\section{Analysis of Tacrolimus blood trough level test (C0)}

The samples ( $3 \mathrm{ml}$ venous blood) were collected in EDTA tube. The samples were withdrawn just prior to the next dose. Tacrolimus dose, the time of administration of last dose and the time of sampling were usually provided with analysis request; the samples were kept in ice, stored at -20 until analysis within one week of sampling.

Tacrolimus was analysed using The ARCHITECT plus assay which is based on the Chemiluminescent Micro-particle Immunoassay methodology. Manufacturer guidelines were followed for sample pretreatment, calibration and dilation. Sample analyses involve mixing accurately measured $200 \mu \mathrm{L}$ of the sample with $200 \mu \mathrm{L}$ of a precipitation reagent which contain methanol and zinc sulphate. Followed by centrifugation; the clear supernatant was analysed on the ARCHITECT instrument according to manufacturer's instructions. The Instrument was calibrated using the calibrators provided by the manufacturer. The measurement range $(2-30 \mathrm{ng} / \mathrm{ml})$, precision $(\mathrm{CV}$ about $7 \%)$ and limit of detection $(1 \mathrm{ng} / \mathrm{ml})$ in our laboratory meets those specified by the manufacturer [7].

\section{Retrieving relevant demographic and clinical}

The following data were retrieved by the researcher from patient's medical record (classic file and computerized system) and recoded in A data collection form which involved for example following items: Demographics: Age, height, weight and BMI. Medical profile: Source of transplanted kidney, Etiology of ESRD, type of induction therapy, current immunosuppressant medication doses, other medications, adverse effects associated with immunosuppressant therapy, incidence of rejection episodes and all relevant lab investigation including Tacrolimus blood trough level (C0), Lab test: chemistry, haematology, serology and immunology test.

\section{Statistical analysis}

This research uses SPSS 20 software. The findings were processed through descriptive statistics (i.e. mean, SD, and coefficient of variation etc.) and inferential statistics (i.e. testing for significance, using the Chi-square test, t-test, one way Analysis of Variance (ANOVA), correlation and logistic regression). Data are expressed by means $\pm \mathrm{SE}$ were $\mathrm{p}$ value $<0.05$ is considered significant.

\section{Results}

Demographic characteristics and relevant clinical data are presented in Tables 1 and 2, to allow precise comparison with other similar studies. Out of 100 SKTP enrolled in the present study 59 were males and 41 were females, the mean age \pm SD of the patients was $37.4 \pm 14.2$ years.

\begin{tabular}{|l|l|l|l|l|}
\hline Statistics & Age (years) & Height $(\mathbf{m})$ & $\begin{array}{l}\text { Weight } \\
\mathbf{( K g )}\end{array}$ & BMI $\left(\mathbf{K g} / \mathbf{m}^{2}\right)$ \\
\hline Mean \pm SD & $37.4 \pm 14.2$ & $1.58 \pm 0.08$ & $68.8 \pm 18.4$ & $27.3 \pm 6.6$ \\
\hline Median & 34.5 & 1.58 & 68.4 & 26.9 \\
\hline Range & $18-60$ & $1.4-1.78$ & $36.8-125$ & $16.4-47.4$ \\
\hline
\end{tabular}

Table 1: Demographic data for the sample of SKTP (41 male, 59 female, total 100).

\begin{tabular}{|c|c|c|}
\hline Parameter & Relevant findings & $\%$ \\
\hline \multirow[t]{2}{*}{ Place of transplantation } & AFHSR (Khamis Mushate) & 81 \\
\hline & Other places & 19 \\
\hline \multirow[t]{4}{*}{ Etiology of kidney failure* } & Hypertensive nephropathy & 69 \\
\hline & Small kidney +other reasons & 13 \\
\hline & Diabetes mellitus nephropathy & 14 \\
\hline & Unknown & 7 \\
\hline \multirow[t]{2}{*}{ Induction Therapy } & Yes & 89 \\
\hline & Not reported & 11 \\
\hline \multirow[t]{2}{*}{ HBAg } & non-reactive & 97 \\
\hline & Reactive & 3 \\
\hline \multirow[t]{2}{*}{$\mathrm{HCV}$} & non-reactive & 96 \\
\hline & Reactive & 4 \\
\hline HIV & non-reactive & 100 \\
\hline CMV- G & Positive & 100 \\
\hline CMV-M & Negative & 100 \\
\hline \multirow[t]{3}{*}{ Type of Donor } & Non-relative & 23 \\
\hline & Relative & 59 \\
\hline & Deceased & 18 \\
\hline
\end{tabular}

Table 2: Relevant clinical variable in SKTP $(n=100)$. 
Page 3 of 5

The median age was 34.5 years, the age ranged between 18 and 60 years, the mean $\mathrm{BMI} \pm \mathrm{SD}$ of the patients was $27.3 \pm 6.6 \mathrm{Kg} / \mathrm{m}^{2}$. The BMI ranges between 16.4 and $47.4 \mathrm{Kg} / \mathrm{m}^{2}$. The median BMI was 26.9 $\mathrm{Kg} / \mathrm{m}^{2}$.

Kidney Transplantation for the majority of the patients (81\%) was in AFHSR Khamis Mushait. Records showed that most of the patients (89\%) received induction therapy before transplantation. Tacrolimus initial dose was $0.1 \mathrm{mg} / \mathrm{kg} /$ day (twice daily). Limited numbers of the patients were reactive for HBAg and $\mathrm{HCV}$ ( $3 \%$ and $4 \%$ respectively). While all patients were negative for HIV and CMV-M; but they were positive for CMV-G.

Regarding documented etiology of ESRF; hypertension represented the major cause for kidney failure (69\%). Followed by diabetes mellitus (14\%). Glomerulonephritis among other kidney disorders were also documented as less common reasons for kidney failure.

$59 \%$ of the patients in the present study received kidney from first grade relative and $23 \%$ of them received kidney from living nonrelative donors and $18 \%$ of the transplanted kidneys were obtained from deceased persons.

Figure 1 shows the incidence of rejection in view of source of transplanted kidney. Although no significant statistical relationship between the type of donor and incidence of kidney rejection in SKTP (chi-square and Fisher exact tests p-values were $>0.05$ ). The results provided an impression that SKTP received kidney from living related donor showed a relatively lower incidence of rejection episodes compared to those received cadaveric kidney.

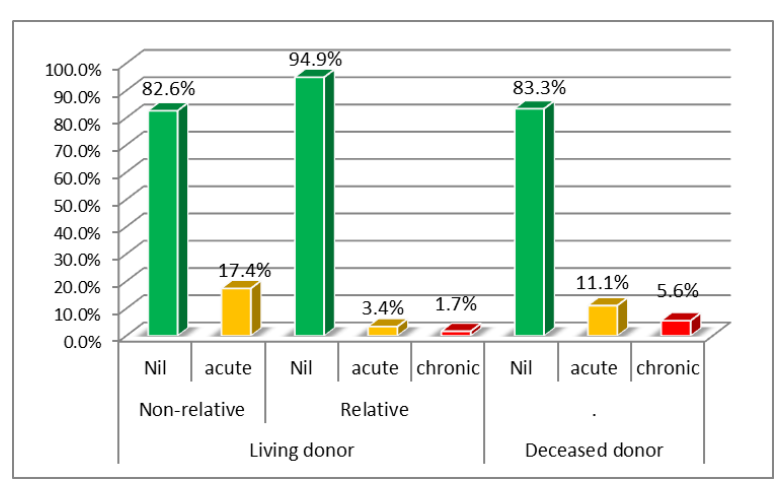

Figure 1: Correlation between type of donor and incidence of renal rejection in SKTP.

Table 3 summarizes Tacrolimus mean trough level $(\mathrm{ng} / \mathrm{ml})$ in different post kidney transplant periods in SKTP classified according to incidence of rejection episodes.

It was noted that the significant relationship between Tacrolimus trough level $(\mathrm{ng} / \mathrm{ml})$ and incidence of kidney rejection was only established in the period after 180 days post transplantation. (P-value $=$ $0.001)$.

In this period, Tacrolimus trough level was $7.4 \pm 0.2$ in patients who showed no rejection; $5.3 \pm 0.7$ for those who suffered acute rejection episodes and $3.8 \pm 0.4$ for those subjected to chronic rejection (Kidney loss). The CV \% which reflects variation between the Tacrolimus level was shown to have its greatest value in SKTP showed acute rejection in all different post kidney transplant periods.

\begin{tabular}{|c|c|c|c|c|c|c|c|}
\hline \multirow[t]{3}{*}{$\begin{array}{l}\text { Time post } \\
\text { transplantation }\end{array}$} & \multirow{2}{*}{\multicolumn{2}{|c|}{ No rejection }} & \multirow{2}{*}{\multicolumn{2}{|c|}{$\begin{array}{l}\begin{array}{l}\text { Acute } \\
\text { rejection }\end{array} \\
\mathrm{N}=8\end{array}$}} & \multirow{2}{*}{\multicolumn{2}{|c|}{$\begin{array}{l}\text { Chronic } \\
\text { rejection }\end{array}$}} & \multirow[t]{3}{*}{$\begin{array}{l}P \\
\text { value }\end{array}$} \\
\hline & & & & & & & \\
\hline & $\begin{array}{l}\text { Mean } \\
\pm \text { SD }\end{array}$ & CV \% & $\begin{array}{l}\text { Mean } \\
\pm \text { SD }\end{array}$ & CV \% & $\begin{array}{l}\text { Mean } \\
\pm \mathrm{SD}\end{array}$ & CV \% & \\
\hline $0-14$ days & $\begin{array}{l}12.12 \\
\pm 2.69\end{array}$ & 22.2 & $\begin{array}{l}11.71 \\
\pm 5.84\end{array}$ & 49.9 & $\begin{array}{l}10.5 \\
\pm 2.33\end{array}$ & 22.2 & $>0.05$ \\
\hline $15-28$ days & $\begin{array}{r}10.23 \\
\pm 2.15\end{array}$ & 21 & $\begin{array}{l}9.69 \\
\pm 5.12\end{array}$ & 52.8 & $\begin{array}{l}8.65 \\
\pm 1.77\end{array}$ & 20.5 & $>0.05$ \\
\hline $29-180$ days & $\begin{array}{l}8.77 \\
\pm 2.29\end{array}$ & 26.1 & $\begin{array}{l}8.16 \\
\pm 2.48\end{array}$ & 30.4 & $\begin{array}{l}6.65 \\
\pm 1.34\end{array}$ & 20.2 & $>0.05$ \\
\hline$>180$ days & $\begin{array}{l}7.37 \\
\pm 1.87\end{array}$ & 25.4 & $\begin{array}{l}5.34 \\
\pm 2.03\end{array}$ & 38 & $\begin{array}{l}3.75 \\
\pm 0.54\end{array}$ & 14.4 & 0.001 \\
\hline
\end{tabular}

Table 3: Mean Tacrolimus trough level at various time post transplantation in SKTP and its relation to incidence of rejection episodes during 24 month follow up period.

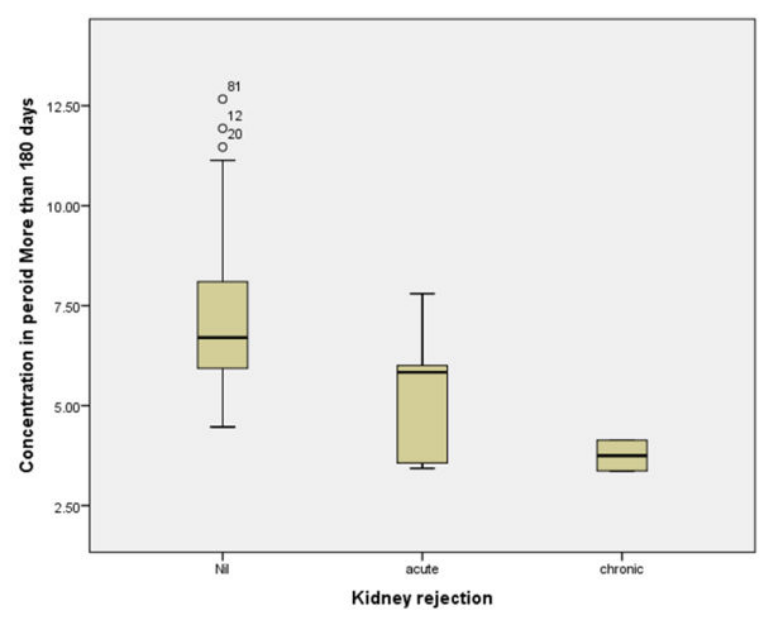

Figure 2: Box plot for median Tacrolimus trough level ( $\mathrm{ng} / \mathrm{ml}$ in the period 6-24 month after transplantation.

\begin{tabular}{|l|l|l|l|}
\hline $\begin{array}{l}\text { Time post } \\
\text { transplantation }\end{array}$ & $\begin{array}{l}\text { Mean } \\
\text { Tacrolimus trough level }\end{array}$ & \multicolumn{2}{|l|}{95 Cl of (TTL) } \\
\hline $0-14$ days & 12.12 & 11.5 & 12.7 \\
\hline $15-28$ days & 10.23 & 9.7 & 10.6 \\
\hline $29-180$ days & 8.77 & 8.2 & 9.2 \\
\hline More than 180 days & 7.37 & 6.9 & 7.8 \\
\hline
\end{tabular}

Table 4: $95 \%$ confidence interval (CI) of Tacrolimus trough level $(\mathrm{TTL})(\mathrm{ng} / \mathrm{ml})$ in SKTP showed no rejection during 24 follow up period.

Figure 2 shows the box plots for the median Tacrolimus trough level $(\mathrm{ng} / \mathrm{ml})$ and incidence of kidney rejection in SKTP in period more 
than 180 days. It was obvious that, as the median trough level of the Tacrolimus decreases as the incidence of rejection increases.

Table 4 shows that $95 \%$ confidence interval (CI) Tacrolimus trough level for the patients who showed no rejection episodes: from 1-14 days, the range was $11.5-12.7(\mathrm{ng} / \mathrm{ml})$; from $15-28$ days, it was $9.7-10.6$ $(\mathrm{ng} / \mathrm{ml})$; for the 29 th-180 days, it was $8.2-9.2(\mathrm{ng} / \mathrm{ml})$ and for more than 180 days, the proposed range was 6.9-7.8 (ng).

\section{Discussion}

\section{Demographic and etiology characteristics}

In National level, the present study was unique regarding the following demographic characteristics: all patients are Saudi with Arabian ethnicity (Khamis Mushate), exclusion of adults less than 18 or greater than 60 years The mean age of our participants was $37.4 \pm$ 14.2 , the majority received the kidney from living related donor (59\%), $23 \%$ non-relatives and only $18 \%$ received kidneys from deceased donors.

The present documented that hypertension as was the major factor for ESRD, followed by diabetes mellitus. Regarding hypertension the present findings is similar to that reported by Khan [8]. National records in SA and epidemiology studies showed high prevalence of diabetes incidence (DM) and high incidence of diabetic nephropathy (DN) among Saudi population El Minshawy and Al-Sayyari $[9,10]$, Hassanien reported variability in prevalence of $\mathrm{DN}$ in different regions [11], Al Suleiman reported that Saudis with DN progress to ESRD faster than other population [12].

\section{Outcome overview}

Within 24 months follow-up period, patient survival was $100 \%, 8 \%$ had acute rejection and $2 \%$ had chronic rejection. All cases of acute rejection were successfully treated by pulse dose of methylprednisolone (500 to1000 mg for 3 to 5 days) but the chronic rejection cases lead to graft loss. In general, although the statistics didn't show significant difference due to limitations in number of patients and other covariates (age, gender) SKTP who received living related kidney showed the lowest incidence of either acute rejection episodes, 3.4\% (2 out of 59) or chronic rejection $1.7 \%$ (1 out of 59), favorable outcome of using living related donor was documented [13].

\section{Therapeutic drug monitoring for Tacrolimus}

The favorable impact of TDM of Tacrolimus on overall clinical outcomes of kidney transplant patients was documented by several studies $[14,15]$. The AUC has been considered as the gold standard to accurately predicate "Tacrolimus systemic exposure "but it is difficult to apply in routine clinical practice. Some studies suggested monitoring of Tacrolimus trough (Cmin, 12 hrs post dose) as an alternative practical approach, However, this approach has many limitations; for example, it didn't clearly distinguish rejection episodes from nephrotoxicity $[6,16]$.

The limited sampling strategy (LSS) (two or three samples) was suggested, as a practical approach to monitor overall exposure to Tacrolimus $[17,18]$. However, its routine use was limited in clinically practice.

At present, C0 is still the standard practical method to monitor Tacrolimus therapy in KTP worldwide.
Earlier clinical trials reported a wide range of 5 to $20 \mathrm{ng} / \mathrm{ml}$ in whole blood $[19,20]$ suggested the target blood trough in the initial 6-12 months post-transplant level as $5-15 \mathrm{ng} / \mathrm{ml}$ and a lower (but still wide range) $5-12 \mathrm{ng} / \mathrm{mL}$ beyond 6-12 months post-transplant, to avoid rejection and minimize adverse effects. Thereafter, guidelines suggested narrower target ranges that varies and depend on concomitant immunosuppressant regimens and time post transplantation [21].

We speculated that, at present, there is no unified international consensus on the optimum Tacrolimus blood trough level concentration in KTP. This may be attributed to variability in immunosuppressant regimens and kidney resources among other variables.

Consequently, the primary aim of the present study was to evaluate the utility and limitation of Tacrolimus blood trough monitoring level to prevent kidney rejection in Saudi population.

\section{The relations between Tacrolimus mean trough level and incidence of kidney rejection}

In the present study, we couldn't establish a clear relationship between mean Tacrolimus trough level and incidence of rejection in the first 6 month post transplantation. But, we documented a very high variability in trough level in those patients who suffered acute rejections (CV about 50\% in the first month).

On other hand, we documented a significant relationship between the Tacrolimus trough level $(\mathrm{ng} / \mathrm{ml})$ and the incidence of kidney rejection after a period of 180 days post-transplantation. In this period, Tacrolimus mean trough level was $7.4 \pm 0.2$ in SKTP with nil rejection versus $5.3 \pm 0.7$ for those with acute rejection and $3.8 \pm 0.4$ for those with chronic rejection. Furthermore, the CV\% which reflects both inter and intra individual variation in Tacrolimus level was obviously high in SKTP showed acute rejection in all different post kidney transplant periods.

We speculate that this extensive variability in trough level represents a risk factor for the incidence of rejection, especially, in the first 6 month post transplantation.

The following variables were suggested to explain the variability in trough levels, especially, in the first 6 month post transplantation: 1Administration of high dose of corticosteroids, consequently, possible variable effects on Tacrolimus metabolism mediated by CYP3A4 etc. [22]. 2-Dose-dependent first pass metabolism [23]. 3-Inter individual variability (genetically based) in bioavailability and metabolism of Tacrolimus mediated through CYP \& P-GP [24-26]. 4- Multiple drug interaction with variable net effect on the pharmacokinetic profile of Tacrolimus [27].

\section{Conclusions}

Trough level monitoring during the 1 st 6 month post transplantation and achievement of target level couldn't solely exclude the risk of incidence of rejection. After a period of 180 days posttransplantation, inadequate Tacrolimus trough level $(<5 \mathrm{ng} / \mathrm{ml}$ can lead to chronic rejection (graft loss). Fluctuation in Tacrolimus trough is a major risk factor in incidence of rejection. Monitoring trough level is a valuable tool to adjust the Tacrolimus after 6 month post transplantation and it's recommended to keep within $5-8 \mathrm{ug} / \mathrm{ml}$. Further studies are recommended to evaluate the utility of the LSS for TDM of Tacrolimus in SKTP first 6 months post transplantation. 


\section{References}

1. Krensky AM, Vincenti F, WM B. (2011) Immunosuppressants, Tolerogens, and Immunostimulants. In: Brunton LL LJ, Parker KL (eds). Goodman and Gillman's The Pharmacological basis of therapeutics. 11: New York: McGraw Hill.

2. Taylor AL, Watson CJ, Bradley JA (2005) Immunosuppressive agents in solid organ transplantation: Mechanisms of action and therapeutic efficacy. Crit Rev Oncol Hematol 56: 23-46.

3. Katabathina V, Menias CO, Pickhardt P, Lubner M, Prasad SR (2016) Complications of Immunosuppressive Therapy in Solid Organ Transplantation. Radiol Clin North Am 54: 303-319.

4. Sweetman S (2014) Martindale: the complete drug reference (40th edn). Pharmaceutical Press, London.

5. de Jonge H, Naesens M, Kuypers DR (2009) New insights into the pharmacokinetics and pharmacodynamics of the calcineurin inhibitors and mycophenolic acid: possible consequences for therapeutic drug monitoring in solid organ transplantation. Ther Drug Monit 31: 416-435.

6. Mohammadpour N, Elyasi S, Vahdati N, Mohammadpour AH, Shamsara $\mathrm{J}$ (2011) A review on therapeutic drug monitoring of immunosuppressant drugs. Iran J Basic Med Sci 14: 485-498.

7. Wallemacq P, Goffinet J-S, O'Morchoe S, Rosiere T, Maine GT, et al. (2009) Multi-site analytical evaluation of the Abbott ARCHITECT tacrolimus assay. Ther Drug Monit 31: 198-204.

8. Khan S, Hussain T, Azam H, Salahuddin N (2015) Statistical study of risk factors of End Stage Renal Failure in Peshawar, Pakistan. Open Access Maced J Med Sci 3: 189-194.

9. El Minshawy O, Ghabrah, El Bassuoni E (2014) Diabetic nephropathy as a cause of end-stage renal disease in Tabuk area, Saudi Arabia: a four-year study. Saudi J Kidney Dis Transp 25: 1105-1109.

10. Al-Sayyari AA, Shaheen FA (2011) End stage chronic kidney disease in Saudi Arabia. A rapidly changing scene. Saudi Med J 32: 339-346.

11. Hassanien AA, Al-Shaikh F, Vamos EP, Yadegarfar G, Majeed A (2012) Epidemiology of end-stage renal disease in the countries of the Gulf Cooperation Council: a systematic review. JRSM Short Rep 3: 38.

12. Al Suleiman MH, Kfoury HK, Jondeby MS, Burgos NS, Al Hayyan H, et al. (2008) Progression of diabetic nephropathy in Saudi patients with type 2 diabetes mellitus. The Endocrinologist 18: 230-232.

13. Halimi JM (2013) Low-grade proteinuria and microalbuminuria in renal transplantation. Transplantation 96: 121-130.

14. Rodrigo E, Segundo D, Fernández-Fresnedo G, López-Hoyos M, Benito A, et al. (2015) Within-Patient Variability in Tacrolimus Blood Levels Predicts Kidney Graft Loss and Donor-Specific Antibody Development. Transplantation 100:2479-2485.
15. Shiohira H, Yamada S, Uehara H, Hokama N, Ueda S (2014) Increased plasma tacrolimus concentration after single intravenous administration of voriconazole: a case of drug-drug interaction. Ryukyu Med J 33: 41-44.

16. Gaynor JJ, Ciancio G, Guerra G, Sageshima J, Roth D, et al. (2015) Lower tacrolimus trough levels are associated with subsequently higher acute rejection risk during the first 12 months after kidney transplantation. Transpl Int 29: 216-226.

17. Mathew BS, Fleming DH, Jeyaseelan V, Chandy SJ, Annapandian V, et al. (2008) A limited sampling strategy for tacrolimus in renal transplant patients. Br J Clin Pharmacol 66: 467-472.

18. van Boekel G, Donders A, Hoogtanders K, Havenith T, Hilbrands L, et al. (2015) Limited sampling strategy for prolonged-release tacrolimus in renal transplant patients by use of the dried blood spot technique. Eur J Clin Pharmacol 71: 811-816.

19. Jusko WJ, Thomson AW, Fung J, McMaster P, Wong SH, et al. (1995) Consensus document: therapeutic monitoring of tacrolimus (FK-506). Ther Drug Monit 17: 606-614.

20. Gaston RS (2001) Maintenance immunosuppression in the renal transplant recipient: an overview. Am J Kidney Dis 38: S25-S35.

21. Hardinger K, Brennan DC (2016) Maintenance immunosuppressive therapy in renal transplantation in adults.

22. Lam S, Partovi N, Ting LS, Ensom MH (2008) Corticosteroid interactions with cyclosporine, tacrolimus, mycophenolate, and sirolimus: fact or fiction? Ann Pharmacother 42: 1037-1047.

23. Venkataramanan R, Swaminathan A, Prasad T, Jain A, Zuckerman S, et al. (1995) Clinical pharmacokinetics of tacrolimus. Clin Pharmacokinet 29: 404-430.

24. Cheng Y, Li H, Meng Y, Liu H, Yang L, et al. (2015) Effect of CYP3A5 polymorphism on the pharmacokinetics of tacrolimus and acute rejection in renal transplant recipients: experience at a single centre. Int J Clin Pract Suppl 69: 16-22.

25. Yang TH, Chen YK, Xue F, Han LZ, Shen CH, et al. (2015) Influence of CYP3A5 genotypes on tacrolimus dose requirement: age and its pharmacological interaction with ABCB1 genetics in the Chinese pediatric liver transplantation. Int J Clin Pract Suppl 69: 53-62.

26. Fathy M, Kamal M, Mohy A, Nabil A (2016) Impact of CYP3A5 and MDR-1 gene polymorphisms on the dose and level of tacrolimus among living-donor liver transplanted patients: single center experience. Biomarkers 21: 335-341.

27. Rancic N, Dragojevic-Simic V, Vavic N, Kovacevic A, Segrt Z, et al. (2015) Tacrolimus concentration/dose ratio as a therapeutic drug monitoring strategy: the influence of gender and comedication. Vojnosanitetski pregled 72: 813-822. 